\title{
Gastrointestinal follicular lymphoma: review of the literature.
}

\section{$\operatorname{AUTHOR}(\mathrm{S})$ :}

Yamamoto, Shuji; Nakase, Hiroshi; Yamashita, Kouhei; Matsuura, Minoru; Takada, Mariko; Kawanami, Chiharu; Chiba, Tsutomu

\section{CITATION:}

Yamamoto, Shuji ...[et al]. Gastrointestinal follicular lymphoma: review of the literature.. Journal of gastroenterology 2010, 45(4): 370-388

\section{ISSUE DATE:}

2010-04

URL:

http://hdl.handle.net/2433/126697

\section{RIGHT:}

The original publication is available at www.springerlink.com; この論文 は出版社版でありません。引用の際には出版社版をご確認ご利用くだ さい。; This is not the published version. Please cite only the published version. 


\section{Gastrointestinal follicular lymphoma: review of the literature}

Shuji Yamamoto ${ }^{1,2}$, Hiroshi Nakase ${ }^{1}$, Kouhei Yamashita ${ }^{3}$, Minoru Matsuura $^{1}$, Mariko Takada $^{4}$, Chiharu Kawanami ${ }^{4}$, and Tsutomu Chiba ${ }^{1}$

${ }^{1}$ Department of Gastroenterology and Hepatology, Graduate School of Medicine, Kyoto University, Kyoto, Japan

${ }^{2}$ Research Fellow of the Japan Society for the Promotion of Science

${ }^{3}$ Department of Hematology and Oncology, Graduate School of Medicine, Kyoto University, Kyoto, Japan

${ }^{4}$ Department of Gastroenterology, Kobe City Medical Center General Hospital, Kobe, Japan

\section{Correspondence to:}

Hiroshi Nakase, MD, PhD, Lecturer

Department of Gastroenterology and Hepatology, Graduate School of Medicine, Kyoto University

54 Shogoin Kawahara-cho, Sakyo-ku, Kyoto, 606-8507, Japan

Tel: $+81-75-751-4319$

Fax: +81-75-751-4303

E-mail: hiropy_n@kuhp.kyoto-u.ac.jp

Short title: Gastrointestinal follicular lymphoma 
Yamamoto et al.

\begin{abstract}
Gastrointestinal follicular lymphoma (GI-FL) is a relatively rare disease, accounting for only $1 \%$ to $3.6 \%$ of gastrointestinal non-Hodgkin's lymphoma. Although the duodenum and terminal ileum are considered to be the most common sites of origin, the development of wireless capsule endoscopy and double balloon enteroscopy has increased the detection of GI-FL in every part of the small intestine. Approximately $80 \%$ of patients with GI-FL are estimated to have multiple lesions throughout the entire gastrointestinal tract.

FL is a low-grade lymphoma that usually develops very slowly. If the lymphoma causes no symptoms, immediate treatment may not be necessary. Standard therapy has not yet been established for GI-FL, but chemotherapy, radiotherapy, monoclonal antibody therapy, or a combination of these therapies is sometimes performed based on the therapeutic regimens for nodal FL. Regimens including conventional chemotherapy with rituximab, which achieve high response rates in nodal FL, are commonly used for GI-FL.

The long-term clinical outcome of GI-FL is unclear. The results of a few series on the long-term outcomes of patients with GI-FL treated with conventional therapy indicate a median relapse-free time ranging from 31 to 45 months. On the other hand, in patients with GI-FL who were followed without treatment, the median-time to disease progression was 37.5 months. Thus, whether to initiate aggressive therapy or continue watchful-waiting in cases of GI-FL is a critically important decision. Ongoing research on biomarkers to guide individualized GI-FL therapy may provide invaluable information that will lead to the establishment of a standard therapeutic regimen.
\end{abstract}

Key words: follicular lymphoma, gastrointestinal tract, multiple lymphomatous polyposis 
Yamamoto et al.

\section{INTRODUCTION}

Follicular lymphoma (FL) is one of the most common subtypes of non-Hodgkin's lymphoma in the Western world, although its incidence may be lower in some parts of the world such as Asia [1]. Most cases of FL are initially detected in the lymph nodes and involvement of extranodal sites usually occurs only as a result of disseminated nodal disease [2]. The gastrointestinal (GI) tract is the most common site of extranodal non-Hodgkin's lymphoma (NHL), accounting for $30 \%$ to $40 \%$ of all primary extranodal NHL. [3, 4] The histologic subtypes in most primary GI-NHL are mucosal-associated lymphoid tissue (MALT) lymphoma or high-grade B cell lymphoma [5-8]. GI-FL is rare and the frequency of this entity accounts for $1 \%$ to $3.6 \%$ of GI-NHL [8-10]. The diagnosis, prognosis, and treatment of GI-FL remain largely unknown because of its rare frequency. In this article, the clinical, biologic, and endoscopic characteristics, as well as the outcome of these lymphomas are reviewed based on the literature and our experience.

\section{CLINICAL FEATURES}

To our knowledge, 244 cases with primary GI-FL have been reported with precise descriptions in the English literature [2, 8, 11-57]. The clinical features of 249 GI-FLs, including the 244 reported cases and 5 unpublished cases that we experienced, are summarized in Table 1.

\subsection{Demographic features}

The median age of patients at diagnosis of GI-FL is 56 years (range 26-81), similar to that of nodal FL $[58,59]$. In several case series of GI-FL, a female predominance was observed $[8,11$, 12], but other case series demonstrated an equal sex distribution in GI-FL [15-18]. Sato et al. [18], who reported the largest case series for GI-FL, described an equal sex distribution in GI-FL. Based on the available data of all reported cases, there is an equal sex distribution (122 females 
and 124 males), which is similar to the sex distribution of nodal FL.

In contrast to geographic distribution of nodal FL [1], of the 249 cases with GI-FL, almost $50 \%$ (120) are Japanese cases [8, 13, 14, 17, 19-39]. This geographic predominance may be due to higher frequency of endoscopic examination in Japan compared with the other countries, because $50(84.7 \%)$ of the 59 patients with GI-FL in Japan presented with no symptoms or only vague GI symptoms, while only $29(32.2 \%)$ of 90 patients from other countries were asymptomatic.

\subsection{Clinical symptoms}

In most of the asymptomatic patients with GI-FL, the lesions were incidentally detected during routine esophagogastroduodenoscopy (EGD). Of 150 patients whose clinical symptoms at presentation are described in the literature, 65 (43.3\%) were asymptomatic and $14(9.3 \%)$ complained of vague GI symptoms such as abdominal discomfort or heartburn.

Abdominal pain was present in 43 of 150 patients (28.7\%). Symptoms of intestinal obstruction, such as nausea and vomiting, were present in $12(8.0 \%)$ and symptoms of intestinal bleeding, such as tarry stool or hematochezia, were present in $9(6.0 \%)$. Intestinal obstructions usually occurred in cases with small intestinal lesions, whereas bleeding was observed mostly in cases with colorectal lesions (Table 2). In some cases, patients with GI-FL have a protein losing enteropathy $[16,22,40-43]$.

\subsection{Clinical stage}

In GI-FL, most cases are classified using the Ann Arbor staging system [60] or the Lugano staging classification of GI tract lymphoma, which is a modified version of the Ann Arbor staging system for GI-NHL [61] (Table 3).

Whereas most patients with nodal FL have systemic disease (i.e., stage III or IV) at the time of diagnosis [62], of 193 GI-FL patients with available clinical stage data, $128(66.3 \%)$ were at 
stage I and 52 (26.9\%) were at stage II. Bende et al. [45] and Takata et al. [63] speculated that the low tendency of GI-FL to disseminate outside the GI tract is a distinct entity that originates from local antigen-responsive B cells in the intestinal mucosa. Bende et al. demonstrated that GI-FLs express alpha4beta7 integrin, a well-defined mucosal homing receptor not expressed in nodal FLs. In addition, GI-FL has a higher frequency of grade 1 lymphoma than nodal FL (see Histologic grading). The higher ratio of localized disease in GI-FL, however, may be due to the definition of GI-lymphoma rather than to a different tumor cell origins, because cases with both intestinal and massive extra-intestinal lesions are excluded from primary GI-FL (see Definition of primary GI lymphoma).

On the other hand, GI-FL can involve regional lymph nodes even in cases in which the primary lesion involves only the mucosal or submucosal layer [8, 28, 33, 44, 46]. GI-FL tends to involve only regional lymph nodes, although it occasionally disseminates outside the GI tract and its regional lymph nodes. Yoshino et al. [8] suggested that this discrepancy is likely a result of the intricate muscle layer structures around the ampulla of Vater, because most intramural FL with regional lymph node dissemination involves this location [8, 28, 33].

\subsection{Disease distribution in the GI tract}

GI-FL may infiltrate unifocally or multifocally, and disease distribution is very important for deciding therapy, i.e., radiation therapy may be effective for unifocal local diseases and rituximab therapy with or without chemotherapy may be required for multifocal diseases. A relatively large case series reported that GI-FL predominantly involved the duodenum, especially around the ampulla of Vater, or the terminal ileum unifocally. In the series reported by Sato et al. [18], 40 of 52 cases of extranodal FL (a number of cases with GI-FL were not described) arose in the duodenum, and in another series reported by Shia et al. [15], duodenal FL accounted for 10 
of 26 cases of FL of the GI tract, while Le Brun et al. [11] reported that 55\% of the lymphomas occurred in the small intestine, where they showed a predilection for the terminal ileum. Damaj et al. [12] reported that the most frequent site of involvement was the small intestine, with a predilection for the ileum and ileo-cecal region. Huang et al. [16] reported that the most frequent site was the ileum ( 7 of 13 cases, 54\%) with 4 tumors in the terminal ileum.

On the other hand, some cases of GI-FL have lesions resembling multiple lymphomatous polyposis (MLP). MLP is characterized by numerous polypoid lesions (Figure 1) involving long segments of GI tract and is a very rare entity, accounting for $2 \%$ of primary GI lymphomas [22]. Although first recognized in the 19th century by Briquet, [64] malignant lymphoma that presented as multiple small nodules affecting the long segment of the GI tract had been paid little attention until 1961 when Cornes referred to this disease entity as "multiple lymphomatous polyposis" [65]. MLP was initially considered to be a typical feature of mantle cell lymphoma (MCL) [66], but later studies indicated that MLP comprises a heterogeneous group of neoplasms, including MCL, FL, and MALT lymphomas [20,67]. Since Le Brun et al. [11] reported that 5 of 31 cases $(16.1 \%)$ with GI-FL had a multiple polypoid appearance, several case series on GI-FL demonstrated that $15.0 \%$ to $46.2 \%$ of GI-FL has MLP aspects $[12,16,18]$. In these reports, however, the whole GI tract was not evaluated in all cases. Because MLP involves the long segment of the GI tract and is often discontinuous [23, 65], the frequency of GI-FL cases with MLP may actually be lower than in these reports. Two innovative methods to observe the entire small intestine were recently introduced: wireless capsule endoscopy (WCE) and double balloon enteroscopy (DBE). Both modalities allow high resolution visualization of the whole small intestine (see endoscopic examination). At present, there are 3 case series of GI-FL in which the whole GI tract was examined using EGD, colonoscopy, and DBE. In these reports, the proportion 
of GI-FL with involvement at two or more sites of the GI tract was much higher than that in previous reports on GI-FL. Nakamura et al. [14] reported that 4 of 5 cases (80\%) of GI-FL presented with multiple polypoid lesions resembling MLP in long segments of the jejunum or the ileum. In a case series by Kodama et al. [13], DBE showed new lesions in the jejunum or the ileum in 8 of 11 patients (73\%) in whom GI-FL was detected in the duodenum with EGD. Higuchi et al. [32] reported that jejunoileal FL lesions were detected with DBE in 6 of 7 patients $(85.7 \%)$ with FL in the duodenum.

Data on the disease distribution of GI-FL based on the English literature and our unpublished cases, are summarized in Table 4. Before the introduction of WCE and DBE, it was reported that most GI-FLs were unifocal (176 of 216 cases, $81.5 \%$ ) and the most frequent site was the duodenum (95 cases, $54.0 \%$ ) followed by the ileum including the terminal ileum (28 cases, $15.9 \%$ ). On the other hand, in 33 cases with GI-FL where the entire intestine was examined with endoscopy including WCE or DBE, 24 patients (72.7\%) suffered from GI-FL with multifocal involvement, and the proximal small intestine including the duodenum and the jejunum was the most frequent site of invasion.

Although there is only a small number of cases of GI-FL in which WCE or DBE was performed, the frequency of GI-FL with long segmental GI tract involvement appears to be much higher than previously reported. Further investigation with WCE or DBE will be useful for accurately evaluating the disease distribution of GI-FL.

\section{DIAGNOSIS}

The diagnosis of primary GI-FL consists of two aspects. One is to diagnose FL as a clinicopathologic subset, and the other is to judge whether lymphoma arises from the GI tract or involves the GI tract as a result of dissemination from the primary site. 


\subsection{Definition of primary GI lymphoma}

It is not always possible to determine the primary site of origin of lymphoma involving the GI tract, especially in cases with both GI and extra-GI involvement. There are two possibilities of GI involvement of lymphoma cells. First, lymphoma arising from regions other than the GI tract presents in the GI tract with an advanced stage of generalized disease. Second, primary GI lymphomas can disseminate and involve lymph nodes or other extra-intestinal sites. At present, there is no way to distinguish whether the GI tract is the primary site or a secondary site representing an advanced stage of FL involving the GI tract.

There are several definitions of primary GI lymphoma and at least two of them are widely used. One is the definition by Dawson et al. [68] put forth in 1966 that restricts GI lymphoma as a localized disease without involvement of peripheral or mediastinal lymph nodes, liver or spleen. The other is the definition by Lewin et al. [9], which extends to a wider range of presentations and requires that patients exhibit GI symptoms or a predominant lesion with or without extra-intestinal lesions. In most case series of GI-FL, the definition by Lewin et al. was applied and cases with massive extra-intestinal lesions were excluded from primary GI-FL [11, 12, 15-17].

\subsection{Endoscopic examination}

\subsubsection{Modality of endoscopic examination}

Endoscopic examinations allow for direct observation and biopsy of the GI tract, and biopsy specimens can be subjected to morphologic evaluation as well as immunohistochemical evaluation and molecular analysis. This modality is essential for diagnosing lymphoma, defining the extent of bowel involvement, and assessing the efficacy of treatment. However, it is very difficult to observe entire small intestine with conventional endoscopy, including EGD, 
colonoscopy, and push enteroscopy. The recent development of WCE and DBE has enabled observation of the entire GI tract.

WCE, first reported by Iddan et al. in 2000 [69], transmits images at a rate of two frames per second for over 8 hours, permitting acquisition of over 50000 images [70]. The DBE system developed by Yamamoto et al. [71] in 2003 enables deep insertion of an endoscope to the small intestine by preventing over-stretching of the intestinal tract with an attachable balloon at its tip and a soft overtube with another balloon at the distal end [71]. These methods allow for detailed observation of the mucosa of the deep small intestine and have provided new data regarding the distribution of GI-FL (see Disease distribution in GI tract).

WCE is a noninvasive outpatient procedure; sedation is unnecessary and there is no risk of exposure to x-rays. On the other hand, DBE can be used to obtain biopsy specimens of the small intestine far from the mouth or anus and to perform endoscopic therapeutic interventions, which cannot be done with WCE. Therefore, WCE appears to be suitable for screening examinations and for assessing treatment efficacy, but DBE is recommended for cases in which histologic evaluation is necessary or intestinal stenosis is suspected.

\subsubsection{Characteristic endoscopic findings}

For 183 of 249 cases with GI-FL, a precise description of the endoscopic findings is available and these are summarized in Table 5. In 95 of these cases, endoscopic findings represented whitish small polypoid, confluent or scattered lesions or nodules, with a 1 to 2 -mm diameter (Figure1, 2a, b), described as "multiple polypoid lesions", "multiple whitish small polyps", “dense and numerous sessile polyps", “yellow-whitish multiple granules”, or "multiple nodular lesions". Magnifying endoscopic examination revealed that these whitish small nodules are enlarged and fused villi and that the mucosa of these lesions has a normal appearance, which is 
suggestive of a subepithelial or submucosal lesion (Figure 3) [23, 25, 36, 38]. Endoscopic ultrasonography reveals thickening of the mucosal and submucosal layers of the intestinal wall with multiple hypoechoic granules corresponding to the lesions [19, 25, 26, 44]. These findings suggest that each granule is an enlarged neoplastic follicle that consists of lymphoma cells in the lamina propria, which has been confirmed with histologic examination (Figure 4a-d). Aggregation of such nodules can be unifocal or multifocal throughout the entire GI tract (see Disease distribution in the GI tract) and is characteristic of lymphoid hyperplasia and low grade B cell lymphoma, including MALT lymphoma with follicular colonization, FL, and MCL. In some cases, macroscopic findings alone are not sufficient to distinguish between these disease subsets [20] (Figure 5), and pathologic examinations, immunohistochemical staining, and molecular analysis are necessary in such cases. Because the prognosis for MALT lymphoma, FL, and MCL is quite different [20], it is very important to establish a differential diagnosis of these diseases. Therefore, obtaining biopsy specimens for histopathologic evaluation, including immunohistochemical staining and molecular analysis, is strongly recommended when this characteristic finding is observed.

The second most common finding is a mass lesion with or without ulceration (38 cases). Mass lesions sometimes present with a submucosal tumor-like appearance (Figure 6a, b, Figure 7 a). In approximately $50 \%$ of cases of GI-FL with a mass lesion, however, multiple nodular lesions are observed at other sites in the GI tract (Figure 7 b). Therefore, in most cases with GI-FL, multiple nodular lesions might be observed in the early stage.

Endoscopy usually reveals multiple polypoid lesions in the duodenum, jejunum, ileum, and colon. Detailed macroscopic findings are available for only 2 of 13 cases reported as primary gastric FL [21, 37]. In both cases, the macroscopic appearance of FL was submucosal tumor-like 
(Figure $6 \mathrm{a}, \mathrm{b}$ ) and could not be distinguished from the other subtypes of GI lymphoma, especially diffuse large B cell lymphoma, which is one of the most common types of high-grade gastric lymphoma. Rectal lesions of GI-FL sometimes present as a single elevated mass like a polyp [36]. GI-FL rarely involves the esophagus and there are only 3 cases in which an esophageal lesion was observed [20,22] and in all cases the esophageal lesion presented as a part of MLP.

\subsection{PATHOLOGY AND BIOLOGY}

GI tract and skin are reported to be the most common sites for primary extranodal FL [2]. Primary cutaneous FL is considered to be a distinct entity from nodal FL because of the lack of $t(14 ; 18)(\mathrm{q} 32 ; \mathrm{q} 21)$ and the relatively favorable response to treatment [72-75], although FL in this site shares some features with nodal FL, such as cell morphology and growth pattern. These findings raise the possibility that FL arising in the GI tract can be distinguished from FL normally found in lymph nodes as considered in cutaneous FL. In conclusion, morphologic futures, immunophenotype, and presence of $t(14 ; 18)(\mathrm{q} 32 ; \mathrm{q} 21)$ suggest that primary GI-FL may be more closely related to nodal FL than cutaneous FL or other primary GI-lymphoma, although some reports on GI-FL have emphasized the differences between GI-FL and nodal FL [18, 45, 63].

\subsubsection{Morphology}

\subsubsection{Microscopic findings}

The morphologic features of GI-FL cannot be distinguished from those of nodal FL [45]. In the typical GI-FL case, the follicles are approximately the same size as a mature germinal center, uniform in size, closely packed, and lacking a mantle zone, presenting in the lamina propria of the intestinal mucosa at the early stage (Figure 4 a) and transmural at an advanced stage. The 
centrocytes, which are usually less than twice the size of small lymphocytes and whose nuclei are irregular [76], and centroblasts, which are usually three to four times the size of small lymphocytes and whose nuclei are round but may be irregular [76], of GI-FL are identical to those of normal germinal centers. A starry-sky pattern with phagocytic histiocytes is usually absent in GI-FL [45], as well as nodal FL [76].

In most cases with GI-FL, the tumor cells do not infiltrate and destroy the gland epithelium, i.e., there is no lymphoepithelial lesion, which is one of the characteristic findings of MALT lymphoma. Tzankov et al. [48], however, reported a case with gastric FL in which a lymphoepithelial lesion was observed and Takeshita et al. [77] reported that lymphoepithelial lesions occurred in 2 of 12 CD10-positive diffuse large cell lymphomas of the stomach that had a germinal center B-cell phenotype. Thus, the presence of a lymphoepithelial lesion may not exclude the possibility of FL, especially in gastric lymphoma.

\subsubsection{Histologic grading}

In most cases with GI-FL as well as nodal FL, FL is categorized into three grades based on the Berard criteria [78], according to the number of centroblasts (large nucleolated cells) per high-power field. In nodal FL, several studies suggest that this grading is a good predictor of prognosis, $[79,80]$ and grade $3 b$ FL tends to behave similarly to de novo diffuse large B cell lymphoma with earlier relapses and a shorter survival [81]. Frequencies of grade 1, grade 2, and grade 3 in GI-FL are 84.4\%, 11.3\% and 4.3\%, respectively (Table 6), while those of grade 1, grade 2 , and grade 3 in nodal FL are $40 \%$ to $60 \%, 25 \%$ to $35 \%$, and approximately $20 \%$, respectively [76]. This may be one of the reasons why GI-FL tends to be detected at an earlier stage and have a better overall survival rate than nodal FL (see Clinical stage and Prognosis of

\section{GI-FL).}


Yamamoto et al.

\subsubsection{Immunophenotype}

In GI-FL, as well as nodal FL, tumor cells are positive for pan-B-cell antigens, including CD19, CD20, and CD22, and negative for CD5 and cyclin D1 [45], which are characteristically expressed in MCL and small lymphocytic lymphoma/chronic lymphocytic leukemia [82]. Immunohistochemical staining for CD10 and bcl-2 is useful for distinguishing FL from lymphoid hyperplasia, MALT lymphoma, or MCL [76]. Both CD10 and bcl-2 are expressed in approximately $90 \%$ of cases with GI-FL (Table 7, Figure 4c, d), while normal germinal center cells express CD10 but not bcl-2 (Figure 5d, e). MCL expresses neither CD10 nor bcl-2, and MALT lymphoma is negative for CD10 and occasionally positive for bcl-2 [76].

Bende et al. [45] demonstrated that GI-FL expressed alpha4beta7 integrin, a well-defined mucosal homing receptor and surface $\operatorname{IgA}$, in contrast to nodal FLs, and speculated that GI-FL is a distinct entity that originates from local antigen-responsive B cells in the intestinal mucosa. No other reports, however, have confirmed that GI-FL expresses alpha4beta7 integrin. In addition, only 1 of 23 other cases in which the surface immunoglobulin of tumor cells was examined expressed IgA, and GI-FL most often expressed surface IgM, followed by IgD (Table 7) [16, 19, 22, 34, 46, 47], similar to nodal FL. Therefore, further evaluation is necessary to elucidate whether or not GI-FL has a different immunophenotype, including alpha4beta7 integrin and surface immunoglobulin, compared to nodal FL.

\subsubsection{Genetic features}

In $70 \%$ to $95 \%$ of nodal FL, $t(14 ; 18)(\mathrm{q} 32 ; \mathrm{q} 21)$, which causes a fusion of BCL2 with the immunoglobulin heavy chain joining region and prevents the normal switching off of $B C L 2$, is present [83-85]. On the other hand, most primary cutaneous FL lacks $t(14 ; 18)(\mathrm{q} 32 ; \mathrm{q} 21)$ [72-75]. Thus, in cases with GI-FL, the presence of this chromosomal rearrangement is examined with 
Yamamoto et al.

Southern blotting, polymerase chain reaction (PCR) (Figure 7 c, Figure 8), or fluorescence in situ hybridization (FISH) (Figure $7 \mathrm{~d}$ ).

Southern blotting, PCR, and FISH demonstrated the presence of an IgH/BCL2 rearrangement in $60 \%, 57.1 \%$, and $70 \%$ of GI-FLs, respectively (Table.8), the same frequency as in nodal FL.

PCR analysis for GI-FL seems to be less sensitive than FISH analysis, as described for nodal FL [86-89]. In all cases in which $t(14 ; 18)(\mathrm{q} 32 ; \mathrm{q} 21)$ was not detected by PCR analysis, the breakpoint used for diagnosis was a major break region (MBR) [90], at which the breakpoint is located in only $50 \%$ to $60 \%$ of nodal FL $[86,91]$, and other breakpoints including the minor cluster region (mcr), 3' BCL2, 5' mcr, and intermediate cluster region (icr) [92-95] were not evaluated. Therefore, in such cases additional PCR analysis using primers for other BCL2 breakpoints or FISH analysis may be more sensitive.

FISH and PCR analysis can be performed on fresh, frozen, or fixed paraffin-embedded material [96]. In addition, FISH analysis can demonstrate $\mathrm{IgH/BCL2}$ rearrangement regardless of the location of BCL2 breakpoint and its probes do not require absolute sequence complementarity for detecting the rearrangement [96]. In both nodal FL [86] and GI-FL, FISH analysis seems to be superior to PCR analysis in detecting $t(14 ; 18)(\mathrm{q} 32 ; \mathrm{q} 21)$ (Table 8$)$.

Taken together, the presence of $t(14 ; 18)(\mathrm{q} 32 ; \mathrm{q} 21)$ suggests that primary GI-FL is more closely related to nodal FL than cutaneous FL and demonstrates that the $I g H / B C L 2$ rearrangement is useful for diagnosing GI-FL and nodal FL, with equivocal morphologic and immunophenotypic findings. Given its superior diagnostic sensitivity, FISH should be considered as an initial diagnostic method to detect $t(14 ; 18)(\mathrm{q} 32 ; \mathrm{q} 21)$ or an alternative method for negative cases with PCR, which is a less expensive and faster technique to perform than FISH. Therefore, for diagnosis of GI-FL, biopsy specimens for fixation with formalin and for FISH or PCR analysis 
should be obtained for higher diagnostic sensitivity.

Takata et al. [63] reported that duodenal FL cells showed accumulation of somatic hypermutation and ongoing mutations in spite of the lack of activation induced cytidine deaminase expression and their follicular dendritic cell network formation, which is similar to neoplasic marginal zone-like B cells. In addition, they demonstrated that duodenal FL had a restricted usage of variable region of immunoglobulin heavy chain gene $(V H)$. Duodenal FL of their series had a higher usage of VH4 and VH5 than nodal FL and VH4-34 and VH5-51were detected in many of these cases. They speculated that these findings should indicate that the lymphoma cells are derived from B cells reacting with specific antigens, as in the case of MALT lymphoma, which develops from chronic inflammation such as Helicobacter pylori (HP)-related gastritis.

\section{STAGING}

Accurate staging of GI-FL is important because durable remissions, and in some cases cures, can be achieved with surgical resection or external-beam radiotherapy of the affected area in patients with localized disease. (see GASTROINTESTINAL FOLLICULAR LYMPHOMA

\section{TREATMENT)}

\subsection{Staging procedures}

Staging procedures for GI-FL are almost the same as those routinely used for nodal FL. In addition to a staging work-up, however, including an accurate physical examination, complete hematologic and biochemical examinations, total-body computerized tomography (CT), and bone marrow aspirate and biopsy, evaluation of the whole GI tract using EGD, colonoscopy, and total enteroscopy (i.e., WCE or DBE) are necessary to determine GI-FL staging because GI-FL often involves long segments of the GI tract (see Disease distribution in the GI tract). 
Yamamoto et al.

\subsection{Recent advances in gastrointestinal follicular lymphoma staging}

Fluorine-18 fluorodeoxyglucose positron emission tomography (FDG-PET) scanning has recently emerged as a major imaging modality for the staging and follow-up of patients with lymphoma, especially aggressive lymphomas [98, 99]. FDG-PET scanning has excellent sensitivity and specificity for staging in nodal FL as well, in contrast to other indolent lymphomas, including B-cell small-cell lymphocytic lymphoma, marginal zone lymphoma, and MCL [100-102].

There are few reports in which FDG-PET was performed for staging in GI-FL [24, 32, 37, 41, 44]. In 14 of 16 cases with FL of the small intestine, there were no obvious accumulations of 18F-FDG in the primary lesions. Focal 18F-FDG uptake in the primary site was observed in 1 case with gastric FL [37] and 2 cases with FL of the small intestine [32]. In all of these cases, the primary lesion formed a mass lesion. It is noteworthy that small mediastinal lymph node dissemination was detected with FDG-PET in one gastric FL case (Figure $6 \mathrm{c}$, arrowhead) [37]. In this case, the disseminated lesion above the diaphragm could not be detected with CT, which was performed before FDG-PET examination. In another case with duodenal FL [24], 18F-FDG accumulated in the mesenteric lymph nodes, whereas there was no obvious uptake in the primary site. Therefore, this modality may not be useful for evaluating the spread of the primary lesion, as Hoffman et al. [44] and Higuchi et al. [32] demonstrated, but is useful for evaluating lymph node dissemination.

\section{PROGNOSIS IN PATIENTS WITH GASTROINTESTINAL FOLLICULAR LYMPHOMA}

\subsection{Prognosis of GI-FL}

The long-term clinical outcome of GI-FL remains unclear because there has been no analysis of a 
large population-based registry of survival for patients with GI-FL. In a case series on long-term outcomes of patients with GI-FL, relapse-free median time or median relapse-free survival was similar to that for nodal FL $[12,15]$. Shia et al. [15] reported a median relapse-free survival of 63 months in 25 GI-FL patients. Damaj et al. [12] reported a median time to progression of 37.5 months in 7 patients without any treatment and a median time to recurrence of the disease of 31 months in 18 patients with treatment.

On the other hand, based on all available data reported previously, GI-FL seems to have a better prognosis than nodal FL. There are only five reported cases in which the patients died of GI-FL and 3 patients died of another disease among 249 GI-FL patients [12, 20, 22, 54]. In addition, the median relapse-free survival was 98 months in 96 patients with GI-FL (Figure 9 a), which appears to be a more favorable outcome compared with nodal FL.

In GI-FL, the frequency of grade 1 lymphoma is much higher compared with nodal FL (see Histologic grading), and most GI-FL presents as a localized disease at the time of diagnosis, while most nodal FL involves multiple sites when staging procedures are performed (see Clinical stage). These features may indicate that GI-FL is a distinct entity from nodal FL, and is slower to progress.

There may be other reasons for the better prognosis of GI-FL than nodal FL. When lymphoma cells infiltrate not only the GI tract but also extra-intestinal sites, e.g., peripheral or mediastinal lymph nodes, liver or spleen, most such cases, especially those with massive extra-intestinal lesions, are excluded from primary GI-FL [11, 12, 15-17] because of the inability to distinguish between primary GI-FL with extra-intestinal invasion and secondary GI-FL as a result of dissemination from another site (see Definition of primary GI lymphoma). Second, there are only a few GI-FL patients with a long-term follow-up because of its rarity. The median-follow up 
duration of the reported cases with GI-FL is only 24.5 months, while the median follow-up was more than 50 months in most studies on long-term clinical outcome of nodal FL [103-105].

Grade 1 GI-FL tends to have a better relapse-free survival than grade 2 GI-FL, but the prognosis for grade 3 lymphoma is unclear because of its rarity. Relapse-free survival of grade 1, grade 2, and grade 3 is $61.6 \%$ at 180 months $(n=48), 41.7 \%$ at 112 months $(n=13)$, and $100 \%$ at 108 months ( $n=3$ ), respectively (Figure $9 \mathrm{~b}$ ). The difference in overall survival between each grade is also unknown, as only 5 patients died of GI-FL and 3 died of other diseases based on the available literature $[12,20,22,54]$.

To compare the prognosis between localized GI-FLs ( i.e., stage I or II) and systemic ones (i.e., stage III or IV) is difficult, because only 13 of 193 GI-FL patients (6.7\%) with available clinical stage data had a systemic disease.

\subsection{Recurrence after achieving complete remission in GI-FL}

Of 249 patients with GI-FL, 85 achieved complete remission with various therapies (see GASTROINTESTINAL FOLLICULAR LYMPHOMA TREATMENT). Of those, FL relapsed in 16 cases from 1 to 98 months after achieving complete remission [12, 15-17, 47]. Details about relapsed cases are summarized in Table 9. Median time to recurrence was 44.5 months. Initial treatments to induce remission were surgery (4 cases), radiation (1 case), chemotherapy (4 cases), radiation plus chemotherapy (2 cases), surgery plus chemotherapy (4 cases), and radiation plus surgery following chemotherapy (1 case). It is noteworthy that FL relapsed outside the GI tract, including in extra-abdominal lymph nodes, the spleen, and tonsils in about $50 \%$ of recurrent cases [15-17]. Therefore, not only evaluation of GI-tract using endoscopy and abdominal CT scan, but also whole body evaluation, including gallium scintigram or FDG-PET, should be performed for follow-up studies after achieving complete 
remission. To screen for extra-abdominal relapse, FDG-PET rather than gallium scintigraphy is recommended because of its sensitivity [100] (see Recent advances in gastrointestinal follicular lymphoma staging).

\section{GASTROINTESTINAL FOLLICULAR LYMPHOMA TREATMENT}

Management of GI-FL is controversial, mainly because of its rarity. Damaj et al. [12] reported that there was no significant difference in the prognosis between patients without treatment and those with treatment, as in nodal FL [106-108]. Therefore, a "watch and wait policy" has been adopted in some asymptomatic cases with GI-FL $[13,15,17,18,20,23,54,55]$. In other cases, surgery, radiotherapy, chemotherapy, monoclonal antibody therapy, or the combination of these therapies is performed. In addition, antibiotic therapy has been tried in several cases of GI-FL [7, $17-19,24,25,34,50]$, based on the established efficacy of antibiotics in cases with other indolent GI lymphomas, such as gastric MALT lymphoma or immunoproliferative small intestinal disease (IPSID).

GI-FL treatments and responses are summarized in Table 10.

\subsection{Conventional therapies}

Patients with GI-FL have been treated with surgery, radiotherapy, chemotherapy, or the combination of these therapies. To compare the effect of each therapy with another is difficult, however, because the number of patients receiving each type of treatment is very small and the background of the cases, including clinical stage and duration of follow-up, varies. In general, a complete response was achieved in most patients regardless of treatment modality, reflecting the indolent nature of GI-FL (Table 9) (see Prognosis in patients with gastrointestinal follicular lymphoma).

Chemotherapy for GI-FL is performed based on the therapeutic regimens of nodal FL, especially 
in cases with systemic disease or widespread GI tract involvement.

\subsection{Rituximab-containing regimen}

After the introduction of therapies using the monoclonal antibody against CD20, rituximab, several randomized studies demonstrated that this therapeutic modality with conventional therapies improved not only the complete response rate and the duration of the response, but also the overall survival rate of nodal FL [109-111]. In addition, in GI-FL, immunotherapy using rituximab with or without chemotherapy has been performed $[7,13,16-18,20,24,28,41,42$, 56], although the efficacy of therapy including rituximab has not been compared with that of conventional therapy alone. There seems to be no difference in the response of GI-FL between therapeutic regimens containing rituximab and conventional therapy at present, which may be due to the disease rarity and the favorable nature of the disease (Table 9).

\subsection{Antibiotic therapy}

Growing evidence indicates that some subtypes of marginal zone lymphomas are associated with chronic antigen stimulation by microbial pathogens and that therapy with antibiotics is effective in marginal zone lymphoma of MALT type, including gastric MALT lymphoma and IPSID. Several studies revealed a close association of infection with $H P$ and gastric MALT lymphoma [112-115] and the eradication of $H P$ infection results in lymphoma remission in cases with low-grade MALT lymphoma localized in the stomach [116-122].

IPSID, which is also called "Mediterranean lymphoma" or "alpha heavy chain disease" [123], is a variant of MALT lymphoma in the small intestine. Early-stage IPSID responds to antibiotics such as tetracycline, ampicillin, or metronidazole [124]. Recently Lecuit et al. reported that IPSID is associated with Campylobacter jejuni [125].

Also in GI-FL, some patients were treated with antibiotics using an $H P$ eradication regimen, 
because $H P$ was detected in the stomach or a diagnosis of MALT lymphoma was made at first.

Most GI-FL lesions, however, were unchanged or progressed despite the administration of antibiotic agents $[17,18,24,25,50]$. The fact that antibiotic therapy is ineffective for most cases with GI-FL may indicate that neoplastic follicles of GI-FL are not composed of antigen-driven cells, different from MALT lymphoma [126].

In several cases with GI-FL, however, regression of GI-FL was noted after antibiotic treatment $[14,19,34]$. Toyoda et al. reported a case with duodenal FL that regressed 12 months after eradication of $H P$, although the immunophenotype of the tumor cells was CD10- and bcl-2+, which is characteristic of MALT lymphoma rather than FL [19]. Nakamura et al. [14] described a patient who showed regression of GI-FL at 15 months after antibiotic treatment and Nomura et al. [34] reported that duodenal FL regressed at 12 months after antibiotic therapy. These cases may suggest that tumor cell growth depends on stimulation with antigens originating from the gut lumen via B cell receptors on the tumor cells in some cases with GI-FL, as Bende et al. [45] and Takata et al. [63] speculated.

\section{CONCLUSION}

Although GI-FL is generally considered to be a rare entity, the number of reported cases with GI-FL is increasing. A consensus regarding the management of this disorder, however, has not yet been established. Irrespective of the specific therapy, overall survival of GI-FL appears to be good. Little is known about long-term clinical outcome of GI-FL, especially since treatment with rituximab was introduced. Therefore, further studies are necessary to evaluate how rituximab changes the clinical outcome of GI-FL.

Accurate evaluation of the distribution of the disease, however, is necessary for deciding the treatment modality. WCE and DBE, which provide detailed information about the mucosa of 
Yamamoto et al.

whole small intestine, are useful for localizing GI-FL because of the potential multifocal involvement of the GI tract in many cases. GI-FL tends to be localized in the GI tract and regional lymph nodes at diagnosis, whereas extra-abdominal relapse is observed in about $50 \%$ of recurrent cases. Accordingly, endoscopic examination throughout the entire GI tract and whole body evaluation with FDG-PET is necessary for staging and follow-up studies. 
Yamamoto et al.

\section{REFERENCES}

[1] Anderson JR, Armitage JO, Weisenburger DD. Epidemiology of the non-Hodgkin's lymphomas: distribution of the major subtypes differ by geographic locations. Non-Hodgkin's Lymphoma Classification Project. Ann Oncol. 1998;9:717-20.

[2] Goodlad JR, MacPherson S, Jackson R, Batstone P, White J. Extranodal follicular lymphoma: a clinicopathological and genetic analysis of 15 cases arising at non-cutaneous extranodal sites. Histopathology. 2004;44:268-76.

[3] d'Amore F, Christensen BE, Brincker H, Pedersen NT, Thorling K, Hastrup J, et al. Clinicopathological features and prognostic factors in extranodal non-Hodgkin lymphomas. Danish LYFO Study Group. Eur J Cancer. 1991;27:1201-8.

[4] Cirillo M, Federico M, Curci G, Tamborrino E, Piccinini L, Silingardi V. Primary gastrointestinal lymphoma: a clinicopathological study of 58 cases. Haematologica. 1992;77:156-61.

[5] Morton JE, Leyland MJ, Vaughan Hudson G, Vaughan Hudson B, Anderson L, Bennett MH, et al. Primary gastrointestinal non-Hodgkin's lymphoma: a review of 175 British National Lymphoma Investigation cases. Br J Cancer. 1993;67:776-82.

[6] Koh PK, Horsman JM, Radstone CR, Hancock H, Goepel JR, Hancock BW. Localised extranodal non-Hodgkin's lymphoma of the gastrointestinal tract: Sheffield Lymphoma Group experience (1989-1998). Int J Oncol. 2001;18:743-8.

[7] Nakamura S, Matsumoto T, Iida M, Yao T, Tsuneyoshi M. Primary gastrointestinal lymphoma in Japan: a clinicopathologic analysis of 455 patients with special reference to its time trends. Cancer. 2003;97:2462-73.

[8] Yoshino T, Miyake K, Ichimura K, Mannami T, Ohara N, Hamazaki S, et al. Increased 
incidence of follicular lymphoma in the duodenum. Am J Surg Pathol. 2000;24:688-93.

[9] Lewin KJ, Ranchod M, Dorfman R. Lymphomas of the gastrointestinal tract: a study of 117 cases presenting with gastrointestinal disease. Cancer. 1978;42:693-707.

[10] Filippa DA, Lieberman PH, Weingrad DN, Decosse JJ, Bretsky SS. Primary lymphomas of the gastrointestinal tract: analysis of prognostic factors with emphasis on histological type. Am J Surg Pathol. 1983;7:363-72.

[11] LeBrun DP, Ngan BY, Weiss LM, Huie P, Warnke RA, Cleary ML. Follicular lymphomas of the gastrointestinal tract. Pathologic features in 31 cases and bcl-2 oncogenic protein expression. Am J Pathol. 1992;140:1327-35.

[12] Damaj G, Verkarre V, Delmer A, Solal-Celigny P, Yakoub-Agha I, Cellier C, et al. Primary follicular lymphoma of the gastrointestinal tract: a study of 25 cases and a literature review. Ann Oncol. 2003;14:623-9.

[13] Kodama M, Kitadai Y, Shishido T, Shimamoto M, Fukumoto A, Masuda H, et al. Primary follicular lymphoma of the gastrointestinal tract: a retrospective case series. Endoscopy. 2008;40:343-6.

[14] Nakamura S, Matsumoto T, Umeno J, Yanai S, Shono Y, Suekane H, et al. Endoscopic features of intestinal follicular lymphoma: the value of double-balloon enteroscopy. Endoscopy. 2007;39 Suppl 1:E26-7.

[15] Shia J, Teruya-Feldstein J, Pan D, Hegde A, Klimstra DS, Chaganti RS, et al. Primary follicular lymphoma of the gastrointestinal tract: a clinical and pathologic study of 26 cases. Am J Surg Pathol. 2002;26:216-24.

[16] Huang WT, Hsu YH, Yang SF, Chuang SS. Primary gastrointestinal follicular lymphoma: a clinicopathologic study of 13 cases from Taiwan. J Clin Gastroenterol. 2008;42:997-1002. 
[17] Sentani K, Maeshima AM, Nomoto J, Maruyama D, Kim SW, Watanabe T, et al. Follicular lymphoma of the duodenum: a clinicopathologic analysis of 26 cases. Jpn J Clin Oncol. 2008;38:547-52.

[18] Sato Y, Ichimura K, Tanaka T, Takata K, Morito T, Sato H, et al. Duodenal follicular lymphomas share common characteristics with mucosa-associated lymphoid tissue lymphomas. J Clin Pathol. 2008;6:377-81.

[19] Toyoda H, Yamaguchi M, Nakamura S, Nakamura T, Kimura M, Suzuki H, et al. Regression of primary lymphoma of the ampulla of Vater after eradication of Helicobacter pylori. Gastrointest Endosc. 2001;54:92-6.

[20] Kodama T, Ohshima K, Nomura K, Taniwaki M, Nakamura N, Nakamura S, et al. Lymphomatous polyposis of the gastrointestinal tract, including mantle cell lymphoma, follicular lymphoma and mucosa-associated lymphoid tissue lymphoma. Histopathology. 2005;47:467-78. [21] Kanda M, Ohshima K, Suzumiya J, Haraoka S, Kawasaki C, Sakisaka S, et al. Follicular lymphoma of the stomach: immunohistochemical and molecular genetic studies. J Gastroenterol. 2003;38:584-7.

[22] Hashimoto Y, Nakamura N, Kuze T, Ono N, Abe M. Multiple lymphomatous polyposis of the gastrointestinal tract is a heterogenous group that includes mantle cell lymphoma and follicular lymphoma: Analysis of somatic mutation of immunoglobulin heavy chain gene variable region. Hum Pathol. 1999;30:581-7.

[23] Nakase H, Matsuura M, Mikami S, Chiba T. Magnified endoscopic view of primary follicular lymphoma at the duodenal papilla. Intern Med. 2007;46:141-2.

[24] Tanaka F, Tominaga K, Ochi M, Yamada T, Sasaki E, Shiba M, et al. Primary duodenal lymphoma: successful rituximab treatment and evaluation by FDG-PET. Hepatogastroenterology. 
2007;54:1658-61.

[25] Higuchi K, Komatsu K, Wakamatsu H, Kawasaki H, Murata M, Miyazaki K, et al. Small intestinal follicular lymphoma with multiple tumor formations diagnosed by double-balloon enteroscopy. Intern Med. 2007;46:705-9.

[26] Tanaka S, Onoue G, Fujimoto T, Kosaka T, Yamasaki H, Yasui Y, et al. A case of primary follicular lymphoma in the duodenum confined to the mucosal layer. J Clin Gastroenterol. 2002;35:285-6.

[27] Yamamoto S, Nakase H, Kawanami C. Follicular lymphoma with small intestinal involvement detected by double-balloon enteroscopy. Clin Gastroenterol Hepatol. 2007;5:A24. [28] Zenda T, Masunaga T, Fuwa B, Okada T, Ontachi Y, Kondo Y, et al. Small follicular lymphoma arising near the ampulla of Vater: a distinct subtype of duodenal lymphoma? Int $\mathbf{J}$ Gastrointest Cancer. 2005;36:113-9.

[29] Matsuura M, Nakase H, Mochizuki N. Ileal polyposis caused by follicular lymphoma. Clin Gastroenterol Hepatol. 2007;5:e30.

[30] Sakata Y, Iwakiri R, Sakata H, Fujisaki J, Mizuguchi M, Fukushima N, et al. Primary gastrointestinal follicular center lymphoma resembling multiple lymphomatous polyposis. Dig

Dis Sci. 2001;46:567-70.

[31] Takamura M, Narisawa R, Maruyama Y, Yokoyama J, Fukuhara Y, Kawai H, et al. A primary follicular lymphoma of the duodenum treated successfully with radiation therapy. Intern Med. 2006;45:309-11.

[32] Higuchi N, Sumida Y, Nakamura K, Itaba S, Yoshinaga S, Mizutani T, et al. Impact of double-balloon endoscopy on the diagnosis of jejunoileal involvement in primary intestinal follicular lymphomas: a case series. Endoscopy. 2009;41:175-178. 
[33] Matsuzawa M, Shimodaira K, Nakamura N, Ochi Y, Hosaka S, Kiyosawa K, et al. A case of primary follicular lymphoma of the duodenum with BCL-2 gene rearrangement. J Gastroenterol. $2003 ; 38: 512-3$.

[34] Nomura K, Sekoguchi S, Ueda K, Nakao M, Akano Y, Fujita Y, et al. Differentiation of follicular from mucosa-associated lymphoid tissue lymphoma by detection of $\mathrm{t}(14 ; 18)$ on single-cell preparations and paraffin-embedded sections. Genes Chromosomes Cancer. 2002;33:213-6.

[35] Yoshida N, Nomura K, Matsumoto Y, Nishida K, Wakabayashi N, Konishi H, et al. Detection of BCL2-IGH rearrangement on paraffin-embedded tissue sections obtained from a small submucosal tumor of the rectum in a patient with recurrent follicular lymphoma. World J Gastroenterol. 2004;10:2602-4.

[36] Tanaka S, Nagahara T, Hirakawa T, Ohta T, Fujimoto T, Takada R. Follicular lymphoma of the rectum. Intern Med. 2008;47:1277-8.

[37] Takada M, Yamamoto S. Gastric follicular lymphoma with mediastinal lymph node dissemination detected by FDG-PET. Endoscopy. (in press).

[38] Inoue N, Isomoto H, Shikuwa S, Mizuta Y, Hayashi T, Kohno S. Magnifying endoscopic observation of primary follicular lymphoma of the duodenum by using the narrow-band imaging system. Gastrointest Endosc. 2009;69:158-9.

[39] Esaki M, Matsumoto T, Nakamura S, Suekane H, Ohji Y, Yao T, et al. Capsule endoscopy findings in intestinal follicular lymphoma. Endoscopy. 2007;39:Suppl 1:E86-7.

[40] van Deursen CT, Goedhard JG, Jie KS, Theunissen P. Primary intestinal follicular lymphoma diagnosed by video capsule endoscopy and double-balloon enteroscopy. Endoscopy. 2008;40:Suppl 2:E8-9. 
[41] Sapoznikov B, Morgenstern S, Raanani P, Aviram A, Rabizadeh E, Prokocimer M, et al. Follicular lymphoma with extensive gastrointestinal tract involvement: follow-up by capsule endoscopy. Dig Dis Sci. 2007;52:1031-5.

[42] Ahmed S, Singh A, Krauss J, Wentz T, Gunaratnam NT. Successful treatment of refractory low grade duodenal lymphoma with rituximab, an anti-CD20 monoclonal antibody. Am J Clin Oncol. 2003;26:408-10.

[43] Peters JH, Rondonotti E, Weijmer MC, Mulder CJ, Jacobs MA. Lymphomatous polyposis of the small intestine. Gastrointest Endosc. 2008;67:763-5.

[44] Hoffmann M, Chott A, Püspök A, Jäger U, Kletter K, Raderer M. 18F-fluorodeoxyglucose positron emission tomography (18F-FDG-PET) does not visualize follicular lymphoma of the duodenum. Ann Hematol. 2004;83:276-8.

[45] Bende RJ, Smit LA, Bossenbroek JG, Aarts WM, Spaargaren M, de Leval L, et al. Primary follicular lymphoma of the small intestine alpha4beta7 expression and immunoglobulin configuration suggest an origin from local antigen-experienced B cells. Am J Pathol. 2003;162:105-113.

[46] Chuang SS, Chang ST, Liu H, Ye H, Sheu MJ, Chen MJ, et al. Intramucosal follicular lymphoma in the terminal ileum with nodal involvement. Pathol Res Pract. 2007;203:691-4. [47] Moynihan MJ, Bast MA, Chan WC, Delabie Jan, Wickert RS, Wu G, et al. Lymphomatous polyposis. A neoplasm of either follicular mantle or germinal center cell origin. Am J Surg Pathol. 1996;20:442-52.

[48] Tzankov A, Hittmair A, Müller-Hermelink HK, Rüdiger T, Dirnhofer S. Primary gastric follicular lymphoma with parafollicular monocytoid B-cells and lymphoepithelial lesions, mimicking extranodal marginal zone lymphoma of MALT. Virchows Arch. 2002;441:614-7. 
[49] Straka C, Mielke B, Eichelmann A, Trede I, Ho AD, Möller P. Bcl-2 gene rearrangements in primary B-cell lymphoma of the gastrointestinal tract reveal follicular lymphoma as a subtype. Leukemia. 1993;7:268-73.

[50] Tang Z, Jing W, Lindeman N, Harris NL, Ferry JA. One patient, two lymphomas. Simultaneous primary gastric marginal zone lymphoma and primary duodenal follicular lymphoma. Arch Pathol Lab Med. 2004;128:1035-8.

[51] Freeman HJ, Anderson ME, Gascoyne RD. Clinical, pathological and molecular genetic findings in small intestinal follicle centre cell lymphoma. Can J Gastroenterol. 1997;11:31-34. [52] Rosty C, Brière J, Cellier C, Delabesse E, Carnot F, Barbier JP, et al. Association of a duodenal follicular lymphoma and hereditary nonpolyposis colorectal cancer. Mod Pathol. 2000;13:586-90.

[53] Nadal E, Martinez A, Jiménez M, Ginés A, Campo E, Piqué J, et al. Primary follicular lymphoma arising in the ampulla of Vater. Ann Hematol. 2002;81:228-31.

[54] Poggi MM, Cong PJ, Coleman CN, Jaffe ES. Low-grade follicular lymphoma of the small intestine. J Clin Gastroenterol. 2002;34:155-9.

[55] Born P, Vieth M, Stolte M. Follicular lymphoma of the duodenum. Endoscopy. 2007;39, Suppl 1:E39.

[56] Aguiar-Bujanda D, Quiñones-Morales I, Camacho-Galán R, Llorca-Martínez I, Rivero-Vera JC, Bohn-Sarmiento U, et al. Primary duodenal follicular lymphoma successfully treated with rituximab. Clin Transl Oncol. 2007;9:471-2.

[57] Misdraji J, Fernandez del Castillo C, Ferry JA. Follicle center lymphoma of the ampulla of Vater presenting with jaundice: report of a case. Am J Surg Pathol. 1997;21:484-8.

[58] Gallagher CJ, Gregory WM, Jones AE, Stansfeld AG, Richards MA, Dhaliwal HS, et al. 
Follicular lymphoma: prognostic factors for response and survival. J Clin Oncol. 1986;4:1470-80.

[59] Armitage JO, Weisenburger DD. New approach to classifying non-Hodgkin's lymphomas: clinical features of the major histologic subtypes. Non-Hodgkin's Lymphoma Classification Project. J Clin Oncol. 1998;16:2780-95.

[60] Carbone PP, Kaplan HS, Musshoff K, Smithers DW, Tubiana M. Report of the committee on Hodgkin's disease staging classification. Cancer Res. 1971;31:1860-1.

[61] Rohatiner A, d'Amore F, Coiffier B, Crowther D, Gospodarowicz M, Isaacson P, et al. Report on a workshop convened to discuss the pathological and staging classifications of gastrointestinal tract lymphoma. Ann Oncol. 1994;5:397-400.

[62] The Non-Hodgkin's Lymphoma Classification Project. A clinical evaluation of the International Lymphoma Study Group classification of non-Hodgkin's lymphoma. The Non-Hodgkin's Lymphoma Classification Project. Blood. 1997;89:3909-18.

[63] Takata K, Sato Y, Nakamura N, Kikuti YY, Ichimura K, Tanaka T, et al. Duodenal and nodal follicular lymphomas are distinct: the former lacks activation-induced cytidine deaminase and follicular dendritic cells despite ongoing somatic hypermutations.Mod Pathol. 2009;22:940-9. [64] Cruveilhier J. Maladies de l'estomac et des intestines. In: Cruveilhier J, editor. Anatomic pathologique du corps humain, vol 2, sect. 34. Paris: JB Balliere, 1835-1842:1-6.

[65] Cornes JS. Multiple lymphomatous polyposis of the gastrointestinal tract. Cancer. $1961 ; 14: 249-57$.

[66] Isaacson PG, MacLennan KM, Subbuswamy SG. Multiple lymphomatous polyposis of the gastrointestinal tract. Histopathology. 1984;8:641-56.

[67] Yatabe Y, Nakamura S, Nakamura T, Seto M, Ogura M, Kimura M, et al. Multiple polypoid 
lesions of primary mucosa-associated lymphoid-tissue lymphoma of colon. Histopathology. 1998;32:116-25.

[68] Dawson IM, Cornes JS, Morson BC. Primary malignant lymphoid tumours of the intestinal tract. Report of 37 cases with a study of factors influencing prognosis. Br J Surg. 1961;49:80-9. [69] Iddan G, Meron G, Glukhovsky A, Swain P. Wireless capsule endoscopy. Nature. 2000;405:417.

[70] Swain P. Wireless capsule endoscopy. Gut. 2003;52, Suppl 4: 48-50.

[71] Yamamoto H, Yano T, Kita H, Sunada K, Ido K, Sugano K. New system of double-balloon enteroscopy for diagnosis and treatment of small intestine disorders. Gastroenterology. $2003 ; 125: 1556-7$.

[72] Cerroni L, Arzberger E, Pütz B, Höfler G, Metze D, Sander CA, et al. Primary cutaneous follicle center cell lymphoma with follicular growth pattern. Blood, 2000;95:3922-8.

[73] Franco R, Fernandez-Vazquez A, Rodriguez-Peralto JL, Bellas C, Lopez-Rios F, Saez A, et al. Cutaneous follicular B-cell lymphoma: description of a series of 18 cases. Am J Surg Pathol. $2001 ; 25: 875-83$.

[74] Bergman R, Kurtin PJ, Gibson LE, Hull PR, Kimlinger TK, Schroeter AL.

Clinicopathologic, immunophenotypic, and molecular characterization of primary cutaneous follicular B-cell lymphoma. Arch. Dermatol. 2001;137:432-9.

[75] Child FJ, Russell-Jones R, Woolford AJ, Calonje E, Photiou A, Orchard G, et al. Absence of the $\mathrm{t}(14 ; 18)$ chromosomal translocation in primary cutaneous B-cell lymphoma. Br J Dermatol. 2001;144:735-44.

[76] Harris NL, Ferry JA. Follicular lymphoma. In: Knowles DM, editor. Neoplastic Hematopathology 2nd ed. Baltimore: Lippincott Williams and Wilkins;2001. p. 823-53. 
[77] Takeshita M, Iwashita A, Kurihara K, Ikejiri K, Higashi H, Udoh T, et al. Histologic and immunohistologic findings and prognosis of 40 cases of gastric large B-cell lymphoma. Am J Surg Pathol. 2000;24:1641-9.

[78] Mann R, Berard C. Criteria for the cytologic subclassification of follicular lymphomas: a proposed alternative method. Hematol Oncol. 1982;1:187-92.

[79] Nathwani BN, Metter GE, Miller TP, Burke JS, Mann RB, Barcos M, et al. What should be the morphologic criteria for the subdivision of follicular lymphomas? Blood. 1986;68:837-45. [80] Anderson JR, Vose JM, Bierman PJ, Weisenberger DD, Sanger WG, Pierson J, et al. Clinical features and prognosis of follicular large-cell lymphoma: a report from the Nebraska Lymphoma Study Group. J Clin Oncol. 1993;11:218-24.

[81] Ott G, Katzenberger T, Lohr A, Kindelberger S, Rüdiger T, Wilhelm M, et al. Cytomorphologic, immunohistochemical, and cytogenetic profiles of follicular lymphoma: 2 types of follicular lymphoma grade 3. Blood. 2002;99:3806-12.

[82] de Leon ED, Alkan S, Huang JC, Hsi ED. Usefulness of an immunohistochemical panel in paraffin-embedded tissues for the differentiation of B-cell non-Hodgkin's lymphomas of small lymphocytes. Mod Pathol. 1998;11:1046-51.

[83] Yunis JJ, Frizzera G, Oken MM, McKenna J, Theologides A, Arnesen M. Multiple recurrent genomic defects in follicular lymphoma. A possible model for cancer. N Engl J Med. 1987;316:79-84.

[84] Bakhshi A, Jensen JP, Goldman P, Wright JJ, McBride OW, Epstein AL, et al. Cloning the chromosomal breakpoint of $\mathrm{t}(14 ; 18)$ human lymphomas: clustering around JH on chromosome 14 and near a transcriptional unit on 18. Cell. 1985;41:899-906.

[85] Cleary ML, Smith SD, Sklar J. Cloning and structural analysis of cDNAs for bcl-2 and a 
hybrid bcl-2/immunoglobulin transcript resulting from the $t(14 ; 18)$ translocation. Cell. 1986;47:19-28.

[86] Weinberg OK, Ai WZ, Mariappan MR, Shum C, Levy R, Arber DA. "Minor” BCL2 breakpoints in follicular lymphoma: frequency and correlation with grade and disease presentation in 236 cases. J Mol Diagn. 2007;9:530-7.

[87] Barrans SL, Evans PA, O'Connor SJ, Owen RG, Morgan GJ, Jack AS. The detection of $\mathrm{t}(14 ; 18)$ in archival lymph nodes: development of a fluorescence in situ hybridization (FISH)-based method and evaluation by comparison with polymerase chain reaction. J Mol Diagn. 2003;5:168-75.

[88] Belaud-Rotureau MA, Parrens M, Carrere N, Turmo M, Ferrer J, de Mascarel A, et al. Interphase fluorescence in situ hybridization is more sensitive than BIOMED-2 polymerase chain reaction protocol in detecting IGH-BCL2 rearrangement in both fixed and frozen lymph node with follicular lymphoma. Hum Pathol. 2007;38:365-72.

[89] Einerson RR, Kurtin PJ, Dayharsh GA, Kimlinger TK, Remstein ED. FISH is superior to PCR in detecting $\mathrm{t}(14 ; 18)(\mathrm{q} 32 ; \mathrm{q} 21)-\mathrm{IgH} / \mathrm{bcl}-2$ in follicular lymphoma using paraffin-embedded tissue samples. Am J Clin Pathol. 2005;124:421-9.

[90] Tsujimoto Y, Cossman J, Jaffe E, Croce CM. Involvement of the bcl-2 gene in human follicular lymphoma. Science. 1985;228:1440-3.

[91] Buchonnet G, Jardin F, Jean N, Bertrand P, Parmentier F, Tison S, et al. Distribution of BCL2 breakpoints in follicular lymphoma and correlation with clinical features: specific subtypes or same disease? Leukemia. 2002;16:1852-6.

[92] Cleary ML, Galili N, Sklar J. Detection of a second $t(14 ; 18)$ breakpoint cluster region in human follicular lymphomas. J Exp Med. 1986;164:315-20. 
[93] Buchonnet G, Lenain P, Ruminy P, Lepretre S, Stamatoullas A, Parmentier F, et al.

Characterization of BCL2-JH rearrangements in follicular lymphoma: PCR detection of 3' BCL2 breakpoints and evidence of a new cluster. Leukemia. 2000;14:1563-9.

[94] Willis TG, Jadayel DM, Coignet LJ, Abdul-Rauf M, Treleaven JG, Catovsky D, et al. Rapid molecular cloning of rearrangements of the IGHJ locus using long-distance inverse polymerase chain reaction. Blood. 1997;90:2456-64.

[95] Akasaka T, Akasaka H, Yonetani N, Ohno H, Yamabe H, Fukuhara S, et al. Refinement of the BCL2/immunoglobulin heavy chain fusion gene in $\mathrm{t}(14 ; 18)(\mathrm{q} 32 ; \mathrm{q} 21)$ by polymerase chain reaction amplification for long targets. Genes Chromosomes Cancer. 1998;21:17-29. [96] Gu K, Chan WC, Hawley RC. Practical detection of $t(14 ; 18)$ (IgH/BCL2) in follicular lymphoma. Arch Pathol Lab Med. 2008;132:1355-61.

[97] Kumar R, Maillard I, Schuster SJ, Alavi A. Utility of fluorodeoxyglucose-PET imaging in the management of patients with Hodgkin's and non-Hodgkin's lymphomas. Radiol Clin North Am. 2004;42:1083-100.

[98] Burton C, Ell P, Linch D. The role of PET imaging in lymphoma. Br J Haematol. 2004;126:772-84.

[99] Naumann R, Vaic A, Beuthien-Baumann B, Bredow J, Kropp J, Kittner T, et al. Prognostic value of positron emission tomography in the evaluation of post-treatment residual mass in patients with Hodgkin's disease and non-Hodgkin's lymphoma. Br J Haematol. 2001;115:793-800.

[100] Tsukamoto N, Kojima M, Hasegawa M, Oriuchi N, Matsushima T, Yokohama A, et al. The usefulness of ${ }^{18} \mathrm{~F}$-fluorodeoxyglucose positron emission tomography $\left({ }^{18} \mathrm{~F}\right.$-FDG-PET) and a comparison of ${ }^{18}$ F-FDG-PET with ${ }^{67}$ Gallium scintigraphy in the evaluation of lymphoma: 
relation to histologic subtypes based on the World Health Organization Classification. Cancer. 2007;110:652-9.

[101] Karam M, Novak L, Cyriac J, Ali A, Nazeer T, Nugent F. Role of fluorine-18

fluoro-deoxyglucose positron emission tomography scan in the evaluation and follow-up of patients with low-grade lymphomas. Cancer. 2006;107:175-83.

[102] Wöhrer S, Jaeger U, Kletter K, Becherer A, Hauswirth A, Turetschek K, et al. 18F-fluoro-deoxy-glucose positron emission tomography (18F-FDG-PET) visualizes follicular lymphoma irrespective of grading. Ann Oncol. 2006;17:780-4.

[103] Federico M, Vitolo U, Zinzani PL, Chisesi T, Clò V, Bellesi G, et al. Prognosis of follicular lymphoma: a predictive model based on a retrospective analysis of 987 cases. Intergruppo Italiano Linfomi. Blood. 2000;95:783-9.

[104] Solal-Céligny P, Roy P, Colombat P, White J, Armitage JO, Arranz-Saez R, et al. Follicular lymphoma international prognostic index. Blood. 2004;104:1258-65.

[105] Decaudin D, Lepage E, Brousse N, Brice P, Harousseau JL, Belhadj K, et al. Low-grade stage III-IV follicular lymphoma: multivariate analysis of prognostic factors in 484 patients-a study of the groupe d'Etude des lymphomes de l'Adulte. J Clin Oncol. 1999;17:2499-2505. [106] Ardeshna KM, Smith P, Norton A, Hancock BW, Hoskin PJ, MacLennan KA, et al. Long-term effect of a watch and wait policy versus immediate systemic treatment for asymptomatic advanced-stage non-Hodgkin lymphoma: a randomized controlled trial. Lancet. $2003 ; 362: 516-22$.

[107] Brandt L, Kimby E, Nygren P, Glimelius B. A systematic overview of chemotherapy effects in indolent non-Hodgkin's lymphoma. Acta Oncol. 2001;40:213-23.

[108] Johnson PW, Rohatiner AZ, Whelan JS, Price CG, Love S, Lim J, et al. Patterns of survival 
in patients with recurrent follicular lymphoma: a 20-year study from a single center. J Clin Oncol. $1995 ; 13: 140-7$.

[109] Marcus R, Imrie K, Belch A, Cunningham D, Flores E, Catalano J, et al. CVP chemotherapy plus rituximab compared with CVP as first-line treatment for advanced follicular lymphoma. Blood. 2005;105:1417-23.

[110] Hiddemann W, Kneba M, Dreyling M, Schmitz N, Lengfelder E, Schmits R, et al. Frontline therapy with rituximab added to the combination of cyclophosphamide, doxorubicin, vincristine, and prednisone (CHOP) significantly improves the outcome for patients with advanced-stage follicular lymphoma compared with therapy with CHOP alone: results of a prospective randomized study of the German Low-Grade Lymphoma Study Group. Blood. 2005;106:3725-32.

[111] Herold M, Haas A, Srock S, Neser S, Al-Ali KH, Neubauer A, et al. Rituximab added to first-line mitoxantrone, chlorambucil, and prednisolone chemotherapy followed by interferon maintenance prolongs survival in patients with advanced follicular lymphoma: an East German Study Group Hematology and Oncology Study. J Clin Oncol. 2007;25:1986-1992.

[112] Wotherspoon AC, Ortiz-Hidalgo C, Falzon MR, Isaacson PG. Helicobacter pylori-associated gastritis and primary B-cell gastric lymphoma. Lancet. 1991;338:1175-6. [113] Farinha P, Gascoyne RD. Helicobacter pylori and MALT lymphoma. Gastroenterology. 2005;128:1579-1605.

[114] Parsonnet J, Hansen S, Rodriguez L, Gelb AB, Warnke RA, Jellum E, et al. Helicobacter pylori infection and gastric lymphoma. N Engl J Med. 1994;330:1267-71.

[115] Hussell T, Isaacson PG, Crabtree JE, Spencer J. The response of cells from low-grade B-cell gastric lymphomas of mucosa-associated lymphoid tissue to Helicobacter pylori. Lancet. 
Yamamoto et al.

$1993 ; 342: 571-4$

[116] Wotherspoon AC, Doglioni C, Diss TC, Pan L, Moschini A, de Boni M, et al. Regression of primary low-grade B-cell gastric lymphoma of mucosa-associated lymphoid tissue type after eradication of Helicobacter pylori. Lancet. 1993;342:575-7.

[117] Bayerdorffer E, Neubauer A, Rudolph B, Thiede C, Lehn N, Eidt S, et al. Regression of primary gastric lymphoma of mucosa-associated lymphoid tissue type after cure of Helicobacter pylori infection. MALT Lymphoma Study Group. Lancet. 1995;345:1591-4.

[118] Roggero E, Zucca E, Pinotti G, Pascarella A, Capella C, Savio A, et al. Eradication of Helicobacter pylori infection in primary low-grade gastric lymphoma of mucosa-associated lymphoid tissue. Ann Intern Med. 1995;122:767-9.

[119] Neubauer A, Thiede C, Morgner A, Alpen B, Ritter M, Neubauer B, et al. Cure of Helicobacter pylori infection and duration of remission of low-grade gastric mucosa-associated lymphoid tissue lymphoma. J Natl Cancer Inst. 1997;89:1350-5.

[120] Savio A, Zamboni G, Capelli P, Negrini R, Santandrea G, Scarpa A, et al. Relapse of low grade gastric MALT lymphoma after Helicobacter pylori eradication: true relapse or persistence? Long-term posttreatment follow-up of a multicenter trial in the north-east of Italy and evaluation of the diagnostic protocol's adequacy. Recent Results Cancer Res. 2000;156:116-24.

[121] Fischbach W, Goebeler-Kolve ME, Dragosics B, Greiner A, Stolte M. Long term outcome of patients with gastric marginal zone B cell lymphoma of mucosa associated lymphoid tissue (MALT) following exclusive Helicobacter pylori eradication therapy: experience from a large prospective series. Gut. 2004;53:34-7.

[122] Wundisch T, Thiede C, Morgner A, Dempfle A, Gunther A, Liu H, et al. Long-term follow-up of gastric MALT lymphoma after Helicobacter pylori eradication. J Clin Oncol. 
Yamamoto et al.

2005;23:8018-24.

[123] Seligmann M, Danon F, Hurez D, Mihaesco E, Preud'homme JL. Alpha-chain disease: a new immunoglobulin abnormality. Science. 1968;162:1396-7.

[124] Rambaud J, Halphen M. Immunoproliferative small intestinal disease (IPSID):

relationships with alpha-chain disease and "Mediterranean" lymphomas. Gastroenterol Int.

1989;2:33-41.

[125] Lecuit M, Abachin E, Martin A, Poyart C, Pochart P, Suarez F, et al. Immunoproliferative small intestinal disease associated with Campylobacter jejuni. N Engl J Med. 2004;350:239-48. [126] Suarez F, Lortholary O, Hermine O, Lecuit M. Infection-associated lymphomas derived from marginal zone B cells: a model of antigen-driven lymphoproliferation. Blood.

2006;107:3034-44. 


\section{Figure legends}

Figure 1.

Endoscopic findings of GI-FL in a 52-year-old man. DBE revealed multiple confluent polypoid lesions over approximately $50 \mathrm{~cm}$ of ileum proximal to the ileocecal valve. [29]

Figure 2.

Endoscopic findings of GI-FL in a 57-year-old woman. DBE demonstrated multiple yellow-whitish nodules of various densities in the duodenum and jejunum. [27]

Figure 3.

Endoscopic findings of GI-FL in a 57-year-old woman. EGD showed multiple whitish granules around the major duodenal papilla. Magnified endoscopic view revealed that the white granules comprised enlarged and fused villi. [23]

Figure 4.

Histologic findings of a granular GI-FL lesion in a 75-year-old woman with duodenal FL.

Histologic evaluation of these granules revealed enlarged neoplastic follicles in the lamina propria of the duodenum. Lymphoepithelial lesions were absent (a). The lymphoid follicles comprised predominantly unvarying small-cleaved cells (b). Immunohistochemical staining for both CD10 (c) and bcl-2 (d) was positive. The diagnosis was FL, grade1 according to the WHO classification.

Figure 5. 
Endoscopic and histologic findings of lymphoid hyperplasia in a 61-year-old woman. EGD showed multiple polypoid lesions in the duodenal bulb that resembled GI-FL lesions ( $a, b)$. Biopsy revealed lymphoid follicles with normal architecture in the lamina propria of the duodenum (c). Immunochemical staining of germinal center cells was weakly positive for CD10 (d), but negative for bcl-2 (e). The diagnosis was lymphoid hyperplasia.

Figure 6.

(a, b) Endoscopic findings of gastric FL and (c) FDG-PET findings of gastric FL in a 63-year-old man. EGD revealed a submucosal tumor-like lesion in the cardia of the stomach 3 years previously (a). This lesion progressed slowly and ulceration of the lesion was observed at the time of presentation (b). FDG PET revealed an accumulation of 18F-FDG in this lesion in the stomach (c, arrow). It is noteworthy that small mediastinal lymph node dissemination was detected with FDG-PET in this case (c, arrowhead). [37]

Figure 7.

(a, b) Endoscopic findings of GI-FL, (c) PCR analysis of GI-FL, (d) and FISH analysis of GI-FL in a 47-year-old man. DBE revealed an submucosal tumor-like lesion with ulceration in the middle portion of the small intestine (a). There were small whitish granular lesions on the oral side of the ulcer (b). PCR analysis. IgH/BCL2 rearrangement was detected with probes for MBR (c). FISH analysis. $\mathrm{t}(11 ; 14)(\mathrm{q} 13 ; \mathrm{q} 32)$ was demonstrated by the yellow fusion signals in an abnormal nucleus (d). 
Figure 8.

PCR analysis in an 81-year-old woman with GI-FL. Primers for MBR failed to detect

$t(14 ; 18)(\mathrm{q} 32 ; \mathrm{q} 21)$ (lane 2) and PCR products using primers for mor were observed in lane 3.

Figure 9.

(a) Kaplan-Meier plots of relapse-free survival after achieving complete remission in cases with

GI-FL. (b) Relapse-free survival according to histologic grade. Relapse-free survival of grade 1,

grade 2, and grade 3 was $61.6 \%$ at 180 months $(n=48), 41.7 \%$ at 112 months $(n=13), 100 \%$ at

108 months $(n=3)$, respectively 